\title{
Reacexp: um Sistema Pericial para a Selecção de Reactores Químicos
}

Pedro Saraiva ${ }^{a}$

Fornece-se uma breve descrição dos fundamentos e definiçâo de um sistema pericial e descreve-se com algum pormenor uma aplicação específica de um sistema pericial (Reacexp) que se destina a actuar como consultor nas fases preliminares de projecto de um reactor químico.

\section{Introduçāo}

Como um dos resultados mais significativos das actividades de investigação em inteligência artificial há a destacar a construção de sistemas periciais. Curiosamente, o nascimento destes na Universidade de Stanford durante a década de 70 aparece ligado ao desenvolvimento de um sistema hoje considerado histórico (DENDRAL), que se destinava a identificar estruturas moleculares a partir dos respectivos espectros de massa.

A química tem portanto acompanhado, e desde início, alguns dos mais importantes marcos na história da inteligência artificial.

Actualmente, quando os sistemas periciais estão a atingir uma gama crescente de implementações comerciais e são alvo de múltiplos projectos de investigação, é possível identificar diversas áreas de aplicação, tanto no domínio da química como da engenharia do processo.

Vários são já os sistemas desenvolvidos em Universidades e/ou empresas especializadas e que se destinam a aplicar o conhecimento possuído por peritos na identificação e caracterização de espécies químicas a partir de uma grande diversidade de determinações analíticas, incluindo os diversos tipos de espectroscopia. O mesmo se passa com a síntese de novos compostos e formulação de produtos.

No domínio da engenharia do processo as aplicações são também as mais diversas, indo desde a fase de síntese de «flowsheets» até ao planeamento da produção de uma unidade fabril já existente, passando pelo controlo, projecto, diagnóstico de falhas, etc.

Tanto num caso como noutro, as potencialidades pedagógicas dos sistemas periciais na formação e ensino de alunos e/ou operadores, ainda que surgindo usualmente como um efeito colateral, são extremamente interessantes.

Procuraremos exemplificar algumas das potencialidades desta nova tecnologia através da apresentação de um caso concreto. Antes porém será conveniente ter uma ideia mais concreta daquilo que é um sistema pericial.

\section{Sistemas Periciais e Inteligência Artificial (*)}

Baptizada como tal em 1956, a Inteligência Artificial tem conhecido uma evolução polémica ao longo destas três décadas e meia de desenvolvimento. Inúmeras foram as expectativas, sonhos e frustrações relacionados com as reais potencialidades deste domínio do conhecimento.

Depois de algumas tentativas mais ou menos fracassadas de aplicar métodos gerais na solução de classes alargadas de problemas, nos anos 70 surge uma nova forma de olhar e implementar os processos utilizados por todos nós na resolução dos mais variados tipos de questões: surgem então as primeiras tentativas de construção de sistemas periciais. Não sendo este o local para descrever exaustivamente aquilo que define um sistema pericial nas suas múltiplas vertentes, iremos contudo tentar traçar uma pintura necessariamente breve e simplista daquilo que os caracteriza:

\section{Filosofia Geral}

Num mundo altamente especializado como aquele em que hoje vivemos, é possível encontrar nos mais diversos domínios de conhecimento (tecnologia, ciência, gestão, medicina, direito, etc.) e nas várias organizações (empresas industriais ou de serviços, Universidades, profissões liberais) pessoas reconhecidas como especialistas ou peritas em determinado tipo de actividade.

Reconhecendo que longe vai a era dos enciclopedistas e que soluções eficazes para a maioria dos problemas com que temos de fazer face requerem a aplicação de conhecimentos específicos, a filosofia existencial dos sistemas periciais assenta na crença de que esse conhecimento é a arma mais poderosa para a resolução do mais diverso tipo de problemas. Com o desenvolvimento de um sistema pericial pretende-se transpor para um computador todo o conjunto de metodologias e conhecimentos que fazem com que um determinado indivíduo seja reconhecido como perito num dado conjunto de tarefas.

\section{Implementaçâo}

Depois de definido de forma concreta e detalhada o tipo de

\footnotetext{
assistente do Departamento de Engenharia Química da Universidade de Coimbra, presentemente a realizar estudos de doutoramento no MIT (EUA) * Esta secção baseia-se intẹgralmente em material apresentado em [21].
} 
problemas que o sistema pericial se propõe resolver (por exemplo, diagnóstico de infecções pulmonares), é necessário analisar de forma exaustiva o modo de «atacar o problema» utilizado pelos especialistas no assunto. Na transposição das linhas de raciocínio e estruturação do conhecimento a elas associado (tal como se encontram representadas no cérebro do perito) para uma forma clara, explícita e transparente, reside a parte mais difícil na construção de um sistema pericial. Esta transferência requer em geral o envolvimento e empenhamento simultâneo de alguém que domine a tecnologia dos sistemas periciais (por vezes designado como Engenheiro do Conhecimento), e de um especialista, cujo comportamento na solução de casos concretos é examinado de forma pormenorizada e exaustiva.

Depois de sistematizada convenientemente a «sabedoria» do perito, é relativamente fácil e imediata a sua implementação em computador, dando assim origem a uma primeira versão do sistema pericial. Esta é depois sucessivamente melhorada, até ser atingido um nível de desempenho comparável ao de um verdadeiro especialista.

\section{Componentes}

Um sistema pericial possui essencialmente dois grandes blocos, relativamente autónomos: a Base de Conhecimento e o Sistema de Inferência.

A base de conhecimento é uma «enciclopédia» na qual se encontra representado todo o conhecimento considerado relevante para a resolução de um determinado problema, depois de tratado e extraído dos peritos.

Os modos como este conhecimento pode ser representado são diversos, variando com o tipo de problemas que o sistema pericial de destina a resolver. Contudo, na grande maioria dos sistemas periciais até hoje desenvolvidos, a «sapiência» é exprimida num conjunto de regras. Cada regra pretende reproduzir um tipo específico de conhecimento, possuindo um formato do tipo Se/Então:

Se ... o reactor é do tipo fluido-sólido

e as partículas de sólido não possuem mais de $0.5 \mathrm{~mm}$ e as partículas de sólido e paredes do reactor não causam problemas sérios de erosão ou atrito

e há necessidade de regenerar frequentemente o catalisador

Então ... recomenda-se a utilização de um reactor do tipo Leito Fluidizado

Evidentemente que cada uma destas regras, por si só, pouco resolve. O sistema de inferência permite articular e definir as linhas de raciocínio através das quais o sistema pericial aplica o conhecimento que possui, disperso pelas dezenas ou centenas de regras que constituem a sua base de conhecimento.

\section{Sistemas de Suporte}

Ainda que seja possível construir de raiz um sistema pericial através da utilização de uma linguagem de programação (ainda que linguagens especialmente concebidas para utilização em inteligência artificial, como o LISP, sejam particularmente eficazes, é possível fazê-lo em C, Pascal, FORTRAN ou mesmo BASIC), existem hoje em dia disponíveis no mercado diversos tipos de suportes de desenvolvimento de sistemas periciais. Ainda que às custas de uma diminuição na flexibilidade e liberdade na construção do sistema, estes suportes informáticos reduzem drasticamente o tempo necessário para o implementar.

\section{Reacexp: um consultor no projecto de reactores químicos}

Em qualquer tipo de processo industrial a transformação das matérias-primas em produtos acabados dá-se através de um conjunto sequencial de operações unitárias que decorrem e envolvem diversos tipos de peças de equipamento.

$\mathrm{O}$ projecto individual de cada uma dessas peças de equipamento desenvolve-se em duas fases essenciais:

1) Com base em considerações de natureza heurística e algumas indicações qualitativas, é possível fazer uma decisão preliminar sobre o tipo de equipamento, configuração genérica e definição aproximada de algumas condições operatórias a utilizar.

2) Para as diversas possibilidades abertas em 1) é efectuado um estudo mais detalhado, geralmente associado à utilização de modelos mecanísticos ou empíricos de índole quantitativa. As decisões finais de projecto são tomadas com base nesses mesmos modelos (dimensionamento, determinação exacta de condições operatórias, etc.).

Pela sua própria natureza, parecem óbvias as potencialidades de aplicação da tecnologia dos sistemas periciais à primeira fase do projecto de uma determinada unidade.

Apesar da sua diversidade, é possível enquadrar todas as peças de equipamento dentro de um grupo reduzido de classes, cada qual possuindo características bastante bem definidas. Parece por isso adequado fazer igualmente uso de algumas das propriedades da programação orientada a objectos e proceder a uma descrição hierárquica. Definimos portanto um conjunto de 14 classes genéricas (Figura 1), todas elas pertencentes a uma classe global designada como «Peças de Equipamento».

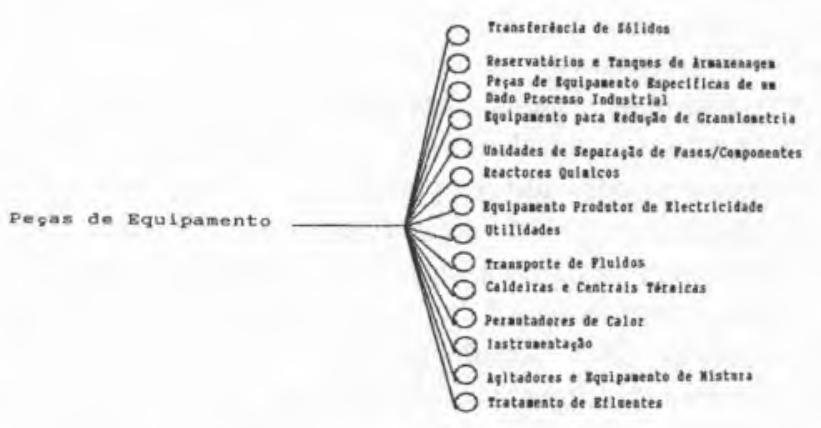

FIGURA 1

Por sua vez, cada classe possui um conjunto de subclasses e/ou propriedades, consideradas pertinentes para caracterizar e descrever cada um dos seus membros.

O sistema pericial por nós desenvolvido, Reacexp, destina-se a ser utilizado como um consultor no projecto de uma das classes acima referida, tendo sido escolhida para o efeito a classe dos reactores químicos. Foi desenvolvido usando um sistema comercial de suporte (NEXPERT). Reacexp possui um total de cerca de 100 regras que representam todo o 
conhecimento que o sistema possui. Depois de recolhido e sistematizado todo esse conhecimento, a sua implementação na forma de um sistema pericial não ocupou mais do que o equivalente a cerca de dois dias de trabalho intensivo.

Cada reactor químico é definido como um objecto que pode ser descrito através de um conjunto de diversas propriedades (Figura 2). O seu projecto será intrinsecamente ligado à reacção de interesse industrial que nele se procura realizar. As propriedades dessa mesma reacção são definidas identificando esta com um outro objecto que faz parte do objecto reactor.

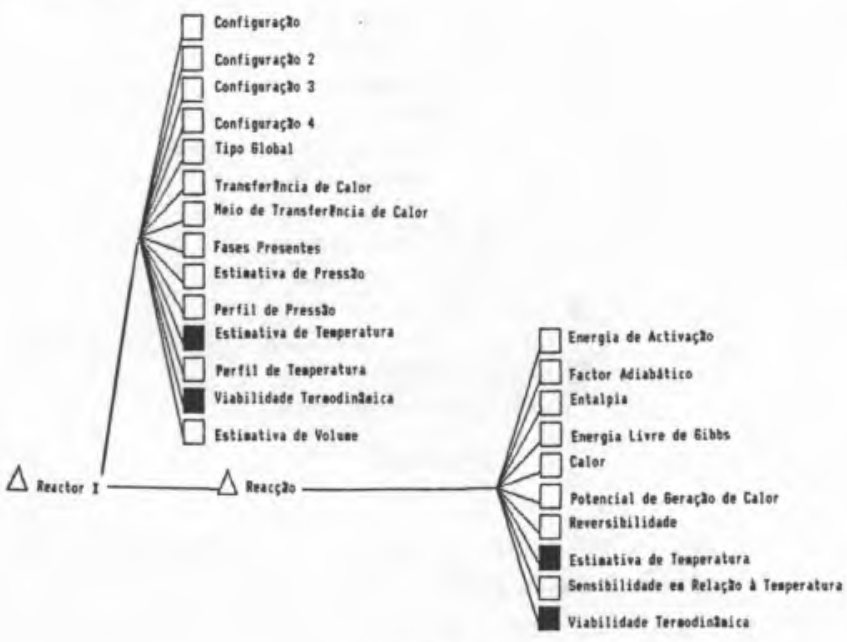

FIGURA 2

Face a um problema concreto, Reacexp estabelece um diálogo progressivo com o utilizador, solicitando o fornecimento de elementos considerados relevantes de acordo com a base de conhecimento e linha de raciocínio seguida. Face à informação disponível, o sistema pericial fornece como resultado final da sessão de consulta um conjunto de sugestões relativamente ao projecto do reactor.

Iremos de seguida proceder a uma descrição mais pormenorizada do conjunto de propriedades consideradas relevantes para a definição de um determinado reactor químico:

\section{Elementos cujo fornecimento é eventualmente solicitado pelo sistema pericial ao utilizador}

* Tipo Global: a um primeiro nível, os reactores podem ser divididos em reactores homogéneos (só uma fase se encontra presente) e heterogéneos (mais do que uma fase envolvida); * Fases Presentes: o utilizador poderá escolher uma de entre as diversas possibilidades (gás-sólido-líquido, gás-sólido, líquido, etc.);

* Estimativa de Pressão: apenas se requer uma ordem de grandeza (nesta fase do projecto os valores exactos de operação são ainda desconhecidos);

* Estimativa da Temperatura: mesmas observações;

* Estimativa de Volume: mesmas observações.

\section{Conclusões Obtidas por Reacexp}

* Configuração: face a um determinado problema específico, Reacexp recomenda a utilização de um ou vários possíveis tipos de reactores (pistão, CSTR, leito fluidizado, etc.);
* Transferência de Calor: de acordo com os elementos fornecidos, o sistema recomenda um modo de operação adiabática ou a transferência simultânea de calor para o reactor;

* Meio de Transferência de Calor: é sugerido o tipo de fluido considerado mais adequado, caso Reacexp tenha optado pelo modo de operação não adiabática;

* Indicações Sobre Pressão: uma recomendação genérica sobre o tipo de perfil de pressão a utilizar pode ser formulada;

* Indicações Sobre Temperatura: as mesmas observações;

* Viabilidade Termodinâmica: a partir do conhecimento do valor da energia livre de Gibbs da reacção é efectuada uma avaliação preliminar sobre a viabilidade prática da mesma do ponto de vista termodinâmico.

De modo análogo, em relação à reacção química em si, há a considerar os seguintes aspectos:

\section{Elementos Eventualmente Solicitados ao Utilizador}

* Energia de Activação

* Entalpia da Reacção

* Energia Livre de Gibbs

* Estimativa da Temperatura

\section{Resultados Desenvolvidos pelo Sistema}

* Tendo por base o valor do Potencial de Geração de Calor (definido em [10]), fornecido pelo utilizador ou calculado pelo próprio Reacexp, a reacção é considerada como sendo Ligeiramente, Moderadamente, Altamente ou Enormemente Exotérmica/Endotérmica, sendo este valor atribuído à propriedade «Calor» do objecto «Reacção». Este atributo é utilizado posteriormente pelo sistema na tomada de diversas decisões relativas ao projecto do reactor.

* A partir dos elementos fornecidos, Reacexp determina o valor da constante de equilíbrio da reacção e, de acordo com este, classifica-a como essencialmente Reversível ou Irreversível.

A base de conhecimento de Reacexp cobre praticamente todos os tipos mais comuns de reactores químicos convencionais, incluindo os diversos tipos de reactores heterogéneos (com duas ou três fases presentes). Pensamos ser esta a primeira vez que o conjunto de regras de natureza heurística disponível na literatura sobre um tão alargado leque de reactores foi integrado e compilado num único sistema. O conhecimento foi recolhido através do tratamento de informação retirada de 24 livros de texto (ver bibliografia) na área da Engenharia da Reacção Química. As decisões tomadas baseiam-se essencialmente em critérios pragmáti$\cos$ e operacionais, mais do que propriamente em apreciações de índole teórica (por exemplo, ainda que um reactor de tipo pistão requeira em geral um menor volume para atingir a mesma conversão numa reacção homogénea em fase líquida, é sabido que em termos de prática industrial é muito mais comum encontrar CSTRs para este tipo de reacção).

As principais limitações do sistema, tal como ele se encontra presentemente, quanto à gama de casos que se encontra apto a analisar, são as seguintes: 
* apenas abrange sistemas onde uma única reacção (ou pseudo-reacção) tenha lugar ou possa ser considerada como dominante;

* estão igualmente excluídos aqueles sistemas em que a fase sólida seja ela própria um reagente.

Depois desta descrição geral do sistema, o melhor será acompanhar uma sessão simulada de consulta, de entre as várias utilizadas para testar o seu funcionamento e avaliar a qualidade das sugestões obtidas.

Consideremos então o seguinte caso:

«Pretende-se projectar um reactor para produção de poliestireno. A reacção decorre na fase líquida e não há necessidade de adicionar qualquer catalisador. $O$ potencial de geração de calor é de 8.9 e a temperatura de operação na ordem dos $423 \mathrm{~K}$. A mistura reactiva é altamente viscosa e o controlo da temperatura no reactor muito importante para a qualidade do produto final. A reacção pode ser considerada irreversível».

Existem diversos modos possíveis para iniciar uma sessão de consulta com Reacexp. Caso o utilizador assim o pretenda, poderá simplesmente manifestar o desejo de ser auxiliado pelo sistema e deixar-se guiar pelas linhas de raciocínio e questões colocadas pelo mesmo. Neste exemplo concreto, dado que existe à partida alguma informação relevante, a sessão é iniciada pelo utilizador, através de um conjunto de indicações fornecidas. Dado que o sistema não possui uma interface de linguagem natural, o seguinte diálogo é uma adaptação do modo de funcionamento interactivo de Reacexp, tal como surge no monitor:

«Utilizador - A reacção que pretendo realizar é irreversível e viável do ponto de vista termodinâmico. O potencial de geração de calor é de 8.9. Quais são os aspectos a considerar em termos de projecto para este reactor?

Reacexp - Preciso que me diga se o reactor é homogéneo ou heterogéneo.

Utilizador - Homogéneo.

Reacexp - E em que fase decorre a reacção?

Utilizador - $\mathrm{Na}$ fase líquida.

Reacexp - Bom, então neste caso há essencialmente que optar, em termos de configuração, entre um CSTR ou um reactor tipo pistão. As regras 11 e 12 da minha base de conhecimento dizem-me que no caso de a reacção ser altamente exotérmica um CSTR seria a melhor alternativa. Preciso portanto de avaliar a exotermicidade da reacção. Para isso disponho também de um conjunto de regras que me permitem concluir, a partir do potencial de geração de calor (fornecido pelo utilizador, mas que eu também poderia ter calculado), que esta reacção é apenas moderadamente exotérmica. Por aqui não posso concluir a favor de um CSTR. Mas a minha regra 10 estabelece que um CSTR é também a solução adequada para este problema no caso de o controlo ou homogeneidade da temperatura no reactor serem essenciais. Posso considerar que assim é?

Utilizador - Sim, de facto o controlo de temperatura é vital para a qualidade final do produto.

Reacexp - Óptimo, então um CSTR ou uma bateria destes parece ser a solução adequada. Vejamos agora o que posso aconselhar em relação à temperatura. Dado que a operação é irreversível, as minhas regras permitem concluir que a temperatura deverá ser tão elevada quanto possível. Finalmente, dado que a reacção é moderadamente exotérmica, a minha regra 3 recomenda que ela se processe com arrefecimento simultâneo do reactor e, atendendo à gama de temperaturas a utilizar, a regra 75 sugere a aplicação de água de arrefecimento como meio de transferência de calor,»

Todos os elementos e conclusões relacionados com uma qualquer sessão de consulta são resumidos e podem ser obtidos por simples observação do objecto que representa o reactor, e que apresenta agora o seguinte aspecto (Figura 3), terminada que foi a sessão de consulta.

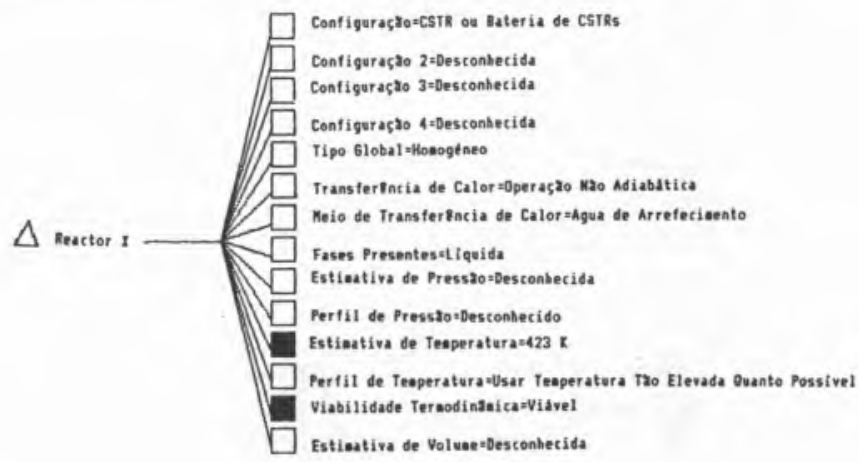

FIGURA 3

À semelhança deste exemplo, testámos o sistema através da apresentação de 6 casos diferentes de reactores actualmente utilizados industrialmente, incluindo reactores homogéneos tubulares (conversão de etano em etileno), catalíticos de leito fixo (produção de amoníaco), multitubulares (produção de anídrido ftálico a partir de xileno), catalíticos de leito fluidizado (conversão de propileno em acrilonitrilo), e trifásicos (hidrogenação de óleos insaturados).

Em qualquer dos casos as recomendações feitas por Reacexp estão em plena concordância com a prática industrial e o tipo de reactores e condições operatórias utilizadas para efectuar as mesmas conversões.

Em resumo, Reacexp possui conhecimento e elabora sugestões em relação aos seguintes quatro grandes grupos de decisões:

\section{Decisões Comuns a Todo o Tipo de Reactores}

1 - Apreciação Qualitativa sobre a Viabilidade Industrial da Reacção do Ponto de Vista Termodinâmico;

2 - Indicação sobre se a reacção deverá ocorrer com transferência de calor ou em condições adiabáticas. No primeiro caso é ainda sugerido o meio de transferência de calor a utilizar;

3 - Recomendação sobre o tipo de perfil de temperatura a utilizar ao longo do reactor.

\section{Decisões Específicas}

4 - Configuração e tipo de reactor considerado mais adequado para efectuar a desejada conversão.

\section{Conclusōes}

Procurou-se com este artigo evidenciar o conjunto de oportunidades que os sistemas periciais podem representar quan- 
do aplicados em diversos domínios da Química e Engenharia do Processo.

Depois de efectuar uma breve apresentação dos princípios e fundamentos dos sistemas periciais, é descrito e analisado um sistema protótipo, Reacexp, destinado a actuar como um consultor no projecto de reactores químicos. Pretende-se também com este exemplo mostrar que, tirando partido dos sistemas comerciais do suporte, é possível implementar num curto espaço de tempo um sistema pericial capaz de produzir resultados bastante interessantes e promissores.

\section{Referências}

[1] Douglas, J., «Conceptual Design of Chemical Processes», McGraw-Hill (1988).

[2] Rudd, Powers \& Siirola, «Process Synthesis», Prentice-Hall (1972).

[3] Levenspiel, O., «Chemical Reactor Engineering», 2nd Edition, John Wiley \& Sons (1972).

[4] Ulrich, G., «A guide to chemical engineering process design and economics», John Wiley \& Sons (1984).

[5] Landau, R. (Editor), «The Chemical Plant», Reinhold Publishing (1966). [6] Liu, Y. et al (Editors), «Recent Developments in Chemical Process and Plant Design», John Wiley \& Sons (1987).

[7] Rudd, D. \& Watson, C., «Strategy of Process Engineering», John Wiley $\&$ Sons (1968).

[8] Wells, G. \& Rose, L., «The art of chemical process design», Elsevier (1986).

[9] Resnick, W., «Process Analysis and Design for Chemical Engineers», McGraw-Hill (1981).

[10] Rase, H., «Chemical Reactor Design for Process Plants», John Wiley \& Sons (1977).

[11] Rose, L., «Chemical Reactor Design in Practice», Elsevier (1981).

[12] Satterfield, C., «Heterogeneous Catalysis in Practice», McGraw-Hill (1980).

[13] Page, J., «Applied Heterogeneous Catalysis», Technip (1987).

[14] Gianetto, A. \& Silveston, P., «Multiphase Chemical Reactors», Hemisphere (1986),

[15] Coulson, J. \& Richardson, J., «Chemical Engineering», vol. 6, Pergamon (1983).

[16] «Perry's Chemical Enginnering Handbook», 5th Edition, McGraw-Hill (1986).

[17] Walas, S., «Chemical Process Equipment», Butterworths (1988).

[18] Denbigh, K. \& Turner, J., «Chemical Reactor Theory», 3rd Edition, Cambridge University Press (1984).

[19] Fogler, H., «Elements of Chemical Reaction Engineering», PrenticeHall (1986).

[20] «Faith, Keyes \& Clark's Industrial Chemicals», 4th Edition, John Wiley \& Sons (1975).

[21] Saraiva, P., «Sistemas Periciais: uma oportunidade», artigo submetido para publicação na Revista da Ordem dos Engenheiros (1990).

[22] McKetta, J. (Editor), «Encyclopedia of Chemical Processing and Design», Marcel Dekker (1976).

[23] Kunii, D. \& Levenspiel, O. «Fluidization Engineering» (1977).

[24] Rachamandran, P. \& Chandhari, R., «Three-Phase Catalyst Reactors» (1983).
Informação Riedel-de Haën: TITULAÇÃO KARL-FISCHER

\section{HYDRANAL Titulação KF perfeita!}

HYDRANAL é a nova geração de reagentes de Karl-Fischer isentos de piridina. Os reagentes HYDRANAL ${ }^{\otimes}$ melhoraram drasticamente as características de titulação, sendo por isso usados em laboratórios de análise espalhados por todo o mundo. Estes reagentes estão patenteados mundialmente.

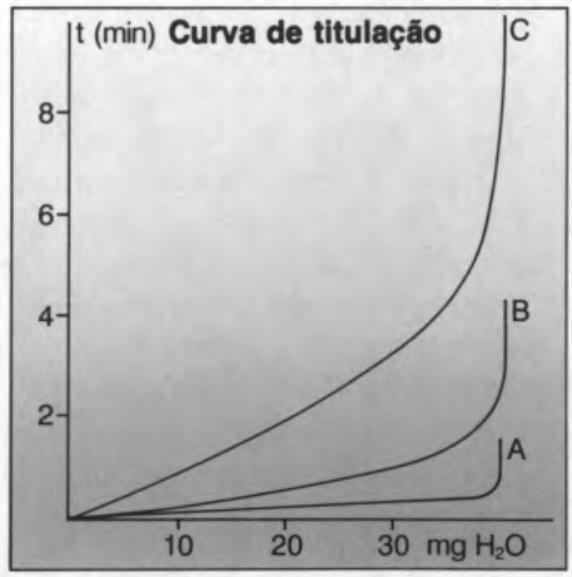

Curva A: Solvente-titulante

HYDRANAL*

(reagente com dois componentes)

Curva B: Compósito HYDRANAL ${ }^{\oplus}$

(reagente monocomponente)

Curva C: Reagentes antigos contendo piridina

\section{Vantagens:}

- titulação rápida

- ponto final estável

- resultados precisos

- isentos de piridina

- isentos de metilglicol

Riedel-de Haën

Aktiengesellschaft

Wunstorfer Str. 40

D-3016 Seelze 1

Telefon (51 37) 7 07-248

Hoechst Portuguesa S.A.

Apartado 6

Estrada Nacional - Lisboa-Sintra

Mem Martins / Portugal

Telefones (1) 9212160 / 9217723

Telex: 16380 Hoelis

Telefax: (Infotec 6510) (1) 9210010 


\section{Convite à Reflexão ...}

\section{Sobre o espírito crítico}

Em Portugal, embora de uma forma aparentemente mansa, tem vindo desde há muito a praticar-se uma política desincentivadora da actividade espiritual. Alternando alguns períodos em que se verifica uma maior liberdade de expressão, com outros submetidos a critérios ético-políticos de vistas curtas e limitativas, tem sido uma constante o clima de esterilidade criadora e de conformismo generalizado. Quer a confusão reinante em períodos de anarquia cultural pouco fecunda, quer a oficialização de uma cultura vigiada e estéril, quer o bulício de uma cultura falsamente promissora, com as suas consequentes gavetas vazias, têm reflectido o mesmo e indisfarçável fenómeno da menoridade intelectual da nação.

Não é necessário criar censuras, nem enviar polícias zelosos, nem entronizar quaisquer anjos negros do mal e da insanidade. Os próprios cenáculos culturais, de inspiração oficial ou comunitária, empresarial ou cooperativa, através de um conjunto de práticas e de hábitos consagrados, resolvem de forma higiénica e quase mecânica o predomínio inconstestado da mediocridade e até da vulgaridade. Sem quase dar por isso, alguns pensadores e artistas de mérito e de renome vão-se convertendo em cúmplices de um estado de coisas que corre o risco de perpetuar-se através de décadas, quiçá de séculos.

Do que se está falando não é só das associações culturais e dos seus corpos gerentes, nem dos prémios e sua consagração na vida social, nem sequer de quem é escolhido pela classe política para representar o País dentro e fora de portas. Porque, de modo fragmentário, até pode estar tudo certo, incluindo os subsídios e bolsas, a presença em congressos ou a escolha de textos para antologias escolares. Aquilo a que queremos referir-nos é, especialmente, ao «espírito» que impõe os critérios de valorização e hierarquização da cultura objectivas e que acaba por determinar o lugar que lhe cabe no corpo de valores nacionais. E são também a seriedade, a sinceridade, a intrínseca honestidade, com que os poderes norteadores da civilização encaram a realidade cultural e de que forma a assimilam, em ordem a transformaremse e aperfeiçoarem-se.

Isto quer simplesmente dizer que nem os benefícios materiais nem os gestos de significado simbólico, desde os subsídios e prémios até às condecorações e elogios públicos, adquirem qualquer relevância se não forem confrontados com os graus de íntima seriedade, de sinceridade e de honestidade com que foram instituídos, atribuídos e aceites.
[...] Em Portugal, tem sido dramática a fulanização da cultura e a mundanização da vida do espírito. De que modo a mediocridade, nas mais variadas circunstâncias, e através das vicissitudes políticas, tem podido contar com a complacência das instituições públicas e privadas, sempre com ar pacífico e quase civilizado, não pode deixar de ser referido e de vir a constituir uma das obrigatórias explicações para o atraso de importantes sectores da vida espiritual, para referirmo-nos especificamente à filosofia, à ciência e à literatura de ficção.

[...] As armas temíveis de que se serve a falange mediocrática são o silêncio fúnebre, a indiferença aparente e a tranquilidade surpreendida. Não se vêem os livros, não se sabe o que dizem, há outras coisas muito mais importantes a tratar. Sugere-se que a falta de qualidade não tem direitos, e que os amores-próprios feridos devem ser entregues aos clínicos da especialidade psiquiátrica. Os poderes públicos, as instituições de classe e as empresas editoriais ficam, através dos graus honoríficos, da política de prémios e dos resultados comerciais, a representar os critérios decisivos de justiça qualificativa.

Para além disto, resta sempre o juízo da história e a sua pressuposta imparcialidade judicativa...

No espaço de tempo que medeia entre o presente e o juízo histórico situa-se o período de pesadelo e de indefinição em que o País tem de viver e trabalhar, em que as classes dirigentes têm de planificar e orientar, e em que a cultura nacional deve preparar os novos amanhãs para a comunidade nacional.

[...] Imanente ao pensamento de todos encontra-se a interrogação de como sair deste impasse, de como quebrar o círculo vicioso que se estabelece na cumplicidade criada entre uma cultura menorizada e uma política inculturizada.

Em nosso entender, a publicação de obras destinadas a esclarecer, informar e preparar o pensamento político nacional adquire carácter de precedência, pois são as pontas de lança do espírito crítico na área da governação e da orientação cultural do País. Em lugar de se envolverem em longos circunlóquios com a cultura oficial e oficializada, cujo aperfeiçoamento retórico faria empalidecer um qualquer sofista da melhor cepa helénica, tais obras visam directamente a classe dirigente e o equacionamento das tarefas que the estão cometidas. Embora vindos da área cultural, e contando com uma preparação de base exigente, tais trabalhos deverão ter em mira um sucesso concreto de cidadania e de prática social.

Romeu de Melo, "Reflexōes 3" 